\title{
Sinonasal Adenocarcinoma: Update on Classification, Immunophenotype and Molecular Features
}

\author{
Ilmo Leivo ${ }^{1}$
}

Received: 17 August 2015/ Accepted: 27 October 2015/Published online: 1 February 2016

(C) The Author(s) 2016. This article is published with open access at Springerlink.com

\begin{abstract}
Adenocarcinomas of the sinonasal tract may originate from respiratory surface epithelium or the underlying seromucinous glands. These malignancies are divided into salivary-type adenocarcinomas and non-salivary-type adenocarcinomas. The latter are further divided into intestinal-type and nonintestinal-type adenocarcinomas. This review provides an update on tumor classification, differential diagnostic considerations and molecular features, as well as new adenocarcinoma entities in the sinonasal area.
\end{abstract}

Keywords Sinonasal adenocarcinoma - Salivary-type adenocarcinoma · Intestinal-type adenocarcinoma .

Nonintestinal-type adenocarcinoma .

Immunohistochemistry - Molecular pathology · Wood dust exposure

\section{Salivary-Type Adenocarcinomas}

Sinonasal salivary-type carcinomas arise from the seromucinous glands and surface epithelium of the nasal cavity and paranasal sinuses [1]. They comprise 5-10\% of sinonasal adenocarcinomas [2].

The histopathological appearances of these tumors are for the most part similar to those of carcinomas and adenomas arising in major and minor salivary glands. Most of the tumor types that occur in major and minor glands also occur in the sinonasal area, with the exception of Warthin

Ilmo Leivo

ilmo.leivo@utu.fi

1 Department of Pathology and Forensic Medicine, University of Turku, Turku, Finland tumor and purely sebaceous salivary tumors [3]. Tumor types include pleomorphic adenoma, myoepithelioma, adenoid cystic carcinoma, mucoepidermoid carcinoma, acinic cell carcinoma, myoepithelial carcinoma, epithelialmyoepithelial carcinoma, salivary duct carcinoma, basal cell adenocarcinoma, polymorphous low-grade adenocarcinoma, carcinoma ex-pleomorphic adenoma, adenocarcinoma, NOS, and others. In the sinonasal tract, pleomorphic adenoma is the most frequent salivary-type tumor [1]. Adenoid cystic carcinoma (AdCC) is the most common salivary-type carcinoma, and the second most common sinonasal malignancy overall after squamous cell carcinoma, and it represents $10-18 \%$ of all sinonasal malignancies [2, 4] (Fig. 1). AdCC usually occurs in the maxillary sinus or the nasal cavity [4]. Tumor type-specific gene rearrangements such as $M Y B-N F I B$ have been described in AdCC also in the sinonasal tract [5]. Longterm prognosis of AdCC is poor due to local spread. Mucoepidermoid carcinoma is less common representing around $5 \%$ of sinonasal glandular tumors [2, 6]. Acinic cell carcinoma, epithelial-myoepithelial carcinoma, polymorphous low-grade adenocarcinoma, adenocarcinoma, NOS, and others are even more rare. Furthermore, rare sinonasal carcinomas have displayed both AdCC-like histological features with surface squamous dysplasia and an HPV-association (particularly of types 33 and 35), but not the $M Y B$ gene rearrangement frequent in AdCC of other organ sites [5].

Awareness of the possibility of salivary-type tumors in the sinonasal tract is important when diagnosing neoplastic lesions in this area. The differential diagnoses of salivarytype carcinomas include intestinal-type adenocarcinoma and nonintestinal-type adenocarcinoma. Furthermore, salivary-type malignancies with clear cell features such as hyalinizing clear cell carcinoma must be differentiated 


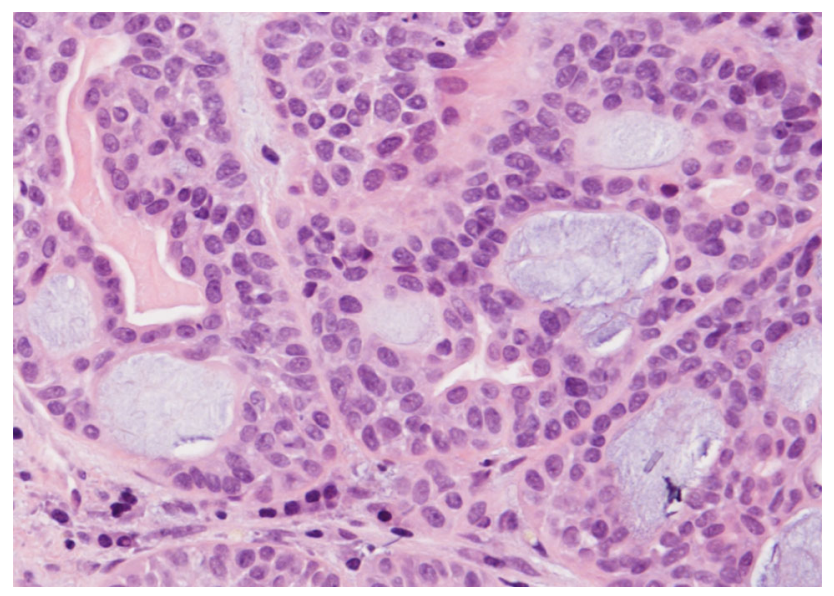

Fig. 1 Adenoid cystic carcinoma of nasal cavity. Classic cribriform pattern with bland nuclear morphology. H-E stain $\times 400$

from renal cell carcinoma metastatic to the sinonasal tract. On the other hand, differential diagnosis of a metastatic renal cell carcinoma should also include the rare sinonasal renal cell-like adenocarcinoma of the sinonasal tract [7].

The treatment of salivary-type tumors is complete surgical removal. The 5-year survival rates have ranged from 40 to $60 \%$, with the poorest results in AdCC [3, 4]. Postoperative radiotherapy has been recommended.

\section{(Non-salivary-Type) Surface Epithelial Adenocarcinomas}

The WHO classifies sinonasal adenocarcinomas of surface epithelial origin in intestinal and nonintestinal types [8].

\section{Intestinal-Type Adenocarcinoma}

Intestinal-type adenocarcinoma (ITAC) is the second most common type of sinonasal adenocarcinoma after AdCC. It is composed of growth patterns that resemble carcinomas or adenomas of intestinal origin, or it may mimic normal histology of the intestinal mucosa [9, 10]. ITACs occur mostly in males in a wide age range with a mean around 50 to 64 years. The tumors are most often localized in the ethmoid sinus ( $40 \%$ ), followed by the nasal cavity ( $25 \%$ ) and the maxillary antrum $(20 \%)$. ITACs are aggressive malignancies, and may spread to adjacent structures including the orbit, the pterygopalatine fossa, the infratemporal fossa and the cranial cavity.

A remarkable association has been identified between long-term exposure to wood dusts and the occurrence of ITAC [11-15]. In woodworking industries, workers with occupational exposure to hardwood dusts may show incidences 1000 times those of the general population. Occupational wood dust exposure has been observed in ca. $20 \%$ of cases. Interestingly, the highest incidences are seen in woodworkers in the furniture industry where hardwoods, particularly beech and oak, are used [13, 16]. Also, ITAC is frequent in long-term wood dust exposure in woodworkers who lay hardwood floors. Also, occupational exposure to dusts in the shoe and leather industry [17] and in textile manufacture, as well as to chromium and nickel, have been incriminated [18]. The carcinogenic compounds have not been identified, but a possible etiologic role for tannins has been suspected [18]. The cumulative exposure time to wood dusts in patients with ITAC has been $40-43$ years [9]. ITACs associated with dust exposure occur predominantly in the ethmoid sinus, while sporadic ITACs often arise in the maxillary antrum.

ITACs mimic the appearance of the mucosa in normal and neoplastic large and small intestine. Based on histologic parameters, Barnes subdivided ITACs into five categories: papillary, colonic, solid, mucinous, and mixed types [9]. The classification of Kleinsasser and Schroeder [19] subdivides ITACs into papillary-tubular cylindrical cell type (corresponding to papillary, colonic, and solid types), alveolar goblet cell type, signet-ring cell type (corresponding to mucinous type), and transitional cell type (corresponding to mixed type). The histologic subtypes have been found to correlate with clinical behavior $[9,18$, 19].

The papillary type (ca. $18 \%$ of ITACs) shows a prominent papillary architecture with few tubular areas (Fig. 2a). Tumors contain columnar goblet cells mimicking intestinal adenomas (Fig. 2b). Occasionally, papillary ITACs may recapitulate normal intestinal mucosa with normal-looking villi, and with the specialized cell types (goblet, resorptive, Paneth, and argentaffin cells) and the muscularis mucosae [20].

The colonic type is the most frequent ITAC (40\%). It displays glandular, tubular and trabecular architecture and few papillae, and resembles a conventional colorectal adenocarcinoma (Fig. 3). Crowded columnar cells with variation in nuclear size and shape line the tumor glands. Intra- and extracellular mucin and few goblet cells may be seen. These tumors are often widely invasive. The solid type comprises less differentiated ITACs with predominantly solid growth patterns. The mucinous type displays mucin-filled glands, or cell clusters that float in pools of extracellular mucin (Fig. 4) and often contain signet-ring cells. Mucinous ITACs closely mimic the mucinous variants of colorectal adenocarcinoma. The mixed type contains a mixture of the preceding types.

The immunophenotype of ITAC includes staining for CK20 (Fig. 5a), CDX2 (Fig. 5b), villin, and MUC2, and variable positivity for CK7 (Fig. 5c) [21-23]. Focal chromogranin A (Fig. 5d) and synaptophysin may be seen in the neuroendocrine cells. A subset of ITACs, mostly in 

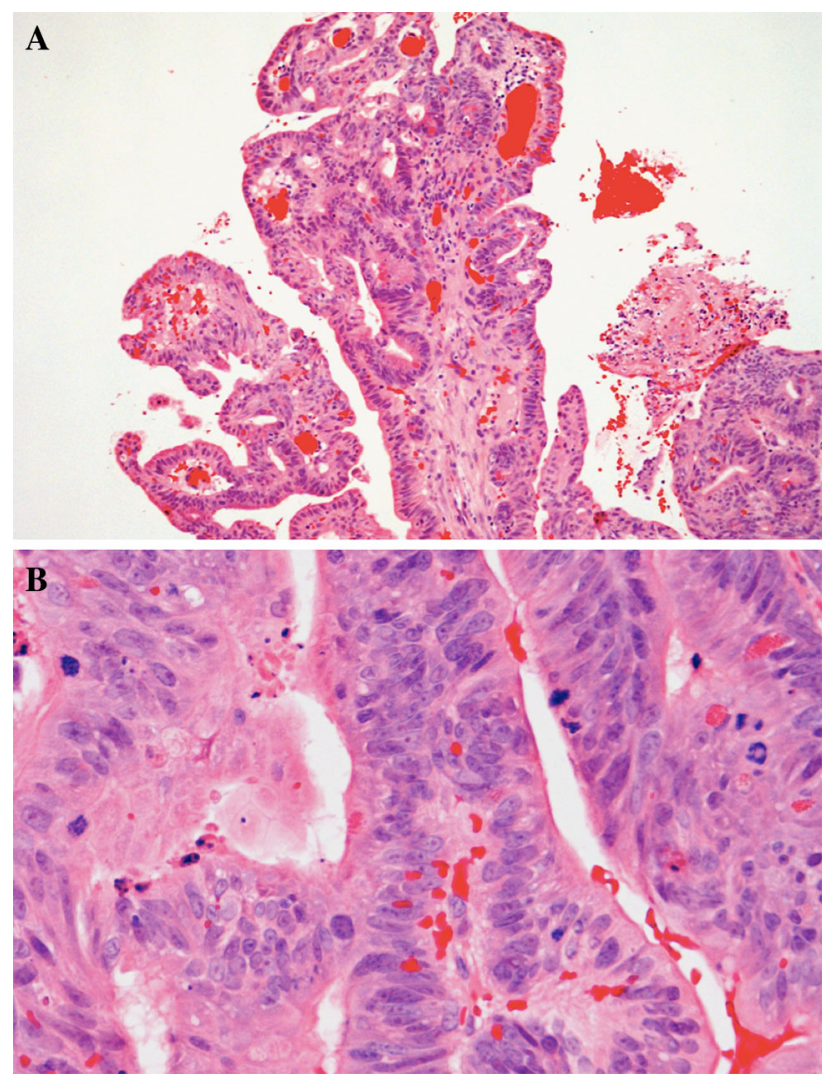

Fig. 2 a Intestinal-type adenocarcinoma, papillary growth pattern. The pattern is composed of papillary projections and glandular and tubular structures. H-E stain $\times 250$. b Tumor of Fig. 3a. The nuclei are elongated, irregular and often hyperchromatic. There is some nuclear piling. Cellular form is mostly cylindrical. There are many mitotic figures. $\mathrm{H}-\mathrm{E}$ stain $\times 400$

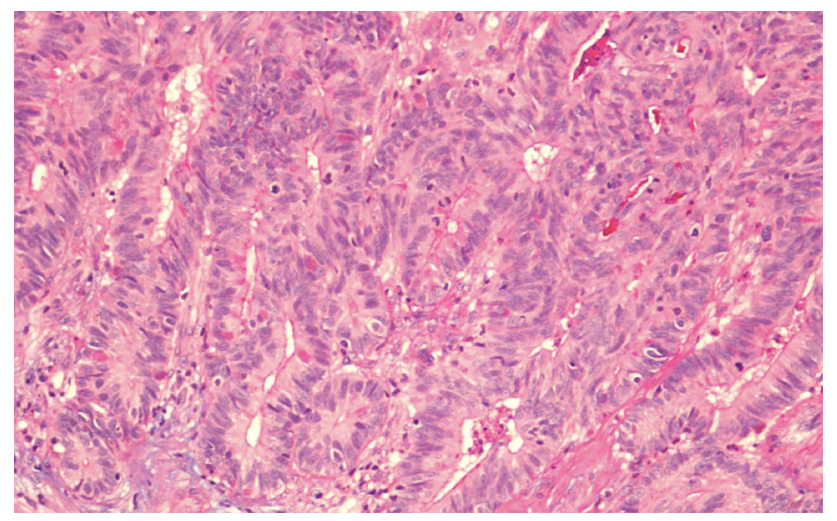

Fig. 3 Intestinal-type adenocarcinoma, colonic growth pattern. Glandular structures and some trabecular areas. High mitotic activity. H-E stain $\times 250$

woodworkers, expressed high levels of EGFR protein [24]. In contrast to colorectal carcinomas, activating mutations of K-RAS and BRAF in the signal route of EGFR are rare [25-27]. This suggests possibilities for anti-EGFR

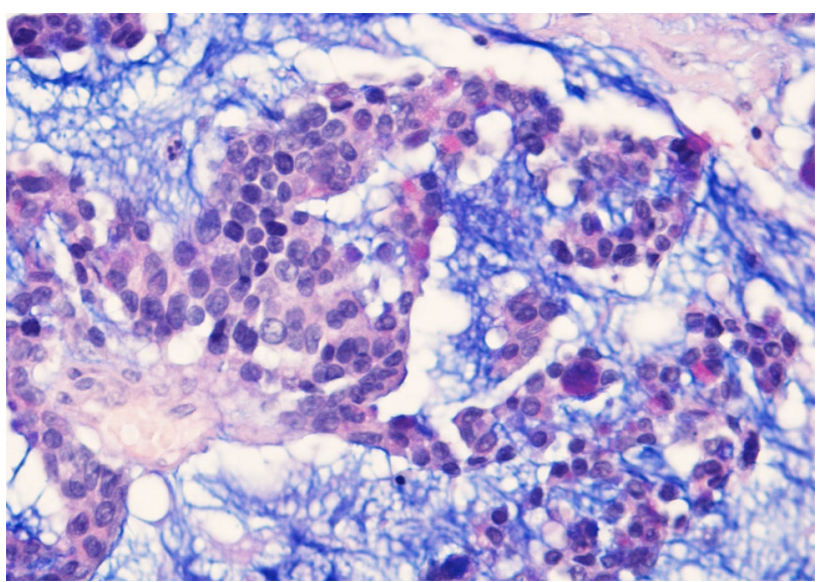

Fig. 4 Intestinal-type adenocarcinoma, mucinous growth pattern. Clusters of tumor cells contain a few goblet-type cells, and are suspended in a pool of Alcian Blue-positive mucin. Alcian-Blue PAS stain $\times 400$

therapies in ITAC. Other molecular studies indicate preserved expression of mismatch repair proteins, $\beta$-catenin and E-cadherin [28], and overexpression of MET protein [29]. Annexin A1 and A2 were down-regulated in ITAC [30]. High prevalence of TP53 mutations was seen in sinonasal carcinoma with work-related exposure to wood dust [31].

Differential diagnosis of ITAC includes metastatic gastrointestinal carcinoma and sinonasal low-grade nonintestinal adenocarcinoma. On grounds of histology and immunophenotype, colonic or mucinous ITAC cannot be distinguished with certainty from colorectal carcinoma metastatic to the sinonasal tract. Both ITACs and colorectal carcinomas express CK20, CDX-2, MUC2, and villin, while the presence of CK7 may be suggestive of ITAC. However, colonoscopy or colorectal radiographic studies should be employed to rule out primary colorectal carcinoma in case of an intestinal-type tumor in the sinonasal tract. Furthermore, while CDX-2 is helpful for diagnosing ITAC, it is not absolutely specific, as it can be expressed also in sinonasal undifferentiated carcinomas and rarely in salivary-type adenocarcinomas. More specific for ITAC than the expression of CDX-2 is the expression of CK20 [32].

The treatment of ITAC is surgical resection varying from lateral rhinotomy and partial maxillectomy to total maxillectomy. Surgery may be combined with radiotherapy.

The behavior of ITAC is that of a high-grade malignancy. In a study of 213 ITACs, $50 \%$ of patients developed recurrences, $8 \%$ had cervical lymph node metastases, $13 \%$ had distant metastases, and $60 \%$ died of their disease [9]. Well differentiated papillary ITACs have an indolent course, but patients with solid and mucinous ITACs have an untoward outcome $[9,18,19]$. 

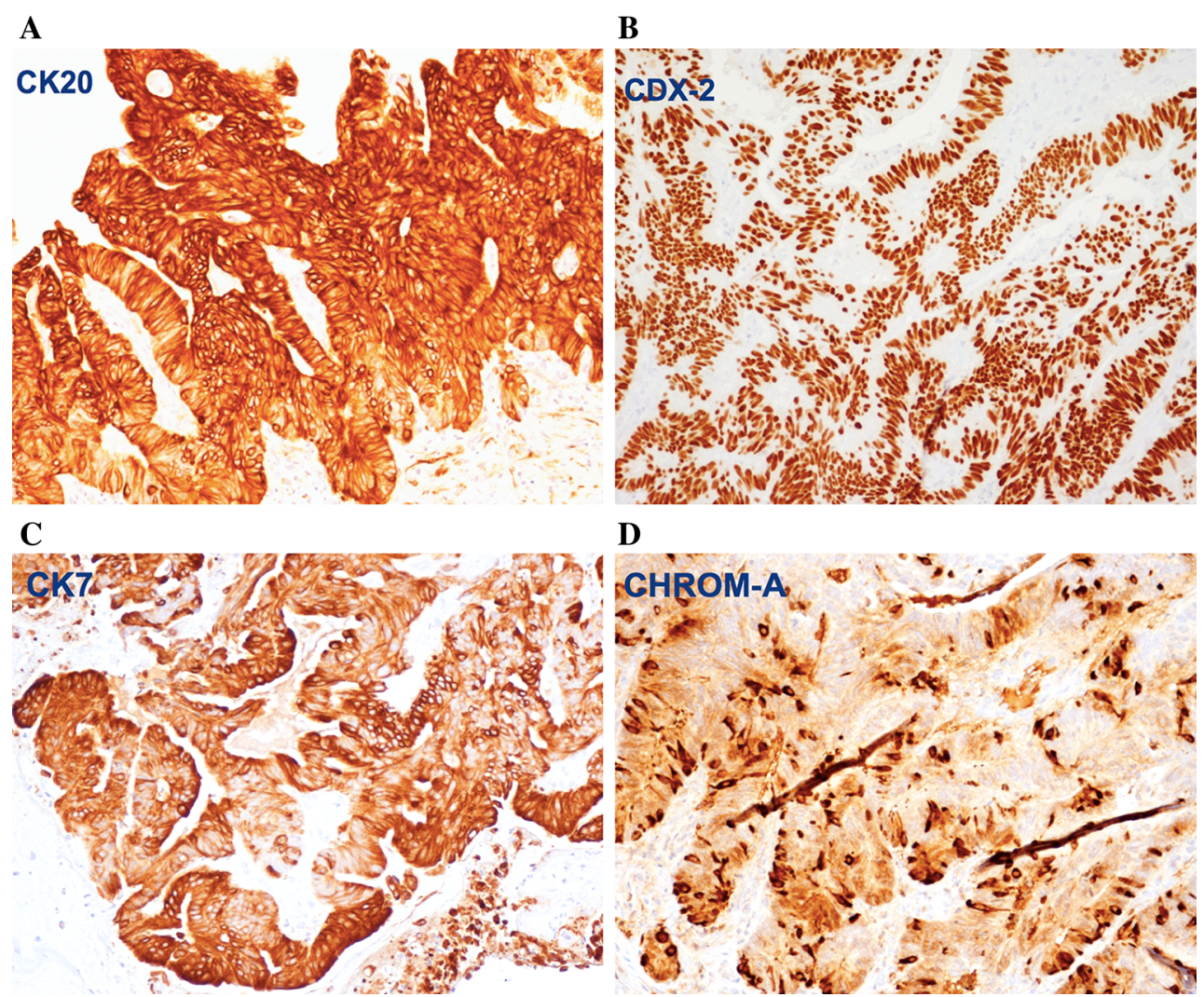

D

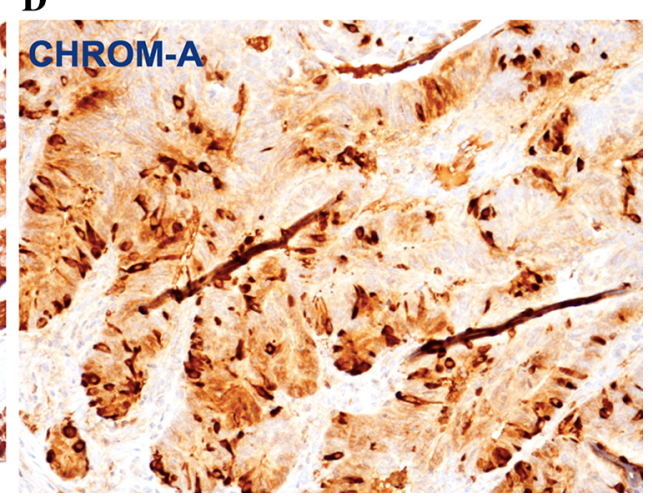

Fig. 5 Immunohistochemical staining of intestinal-type adenocarcinoma, papillary growth pattern, for a CK20, b CDX-2, c CK7, and d chromogranin A. Peroxidase conjugated ABC Kit (Dako) $\times 250$

\section{Nonintestinal-Type Adenocarcinoma}

These adenocarcinomas display histopathologic features of neither sinonasal intestinal-type adenocarcinomas nor salivary-type adenocarcinomas, and they are divided in high-grade and low-grade types [8].

High-grade nonintestinal-type adenocarcinomas are rare malignancies of the sinonasal tract. Patients are frequently males with a wide age range and a mean around 60 years. Histopathologically, these tumors have been reported to display a diversity of morphologic patterns such as blastomatous, apocrine, oncocytic/mucinous, poorly differentiated/undifferentiated, and others [33]. Their nuclei tend to be pleomorphic and there is mitotic activity (Fig. 6). These tumors were reported to lack CDX-2 and CK20 immunoreactivity [33]. The heterogeneous features of these tumors may overlap with those of other malignancies of this area, and consequently other primary and metastatic malignancies must be carefully ruled out before making this diagnosis. In particular, differential diagnosis from salivary-type adenocarcinoma, NOS may be very challenging. The prognosis of high-grade nonintestinaltype adenocarcinomas is poor [33, 34].

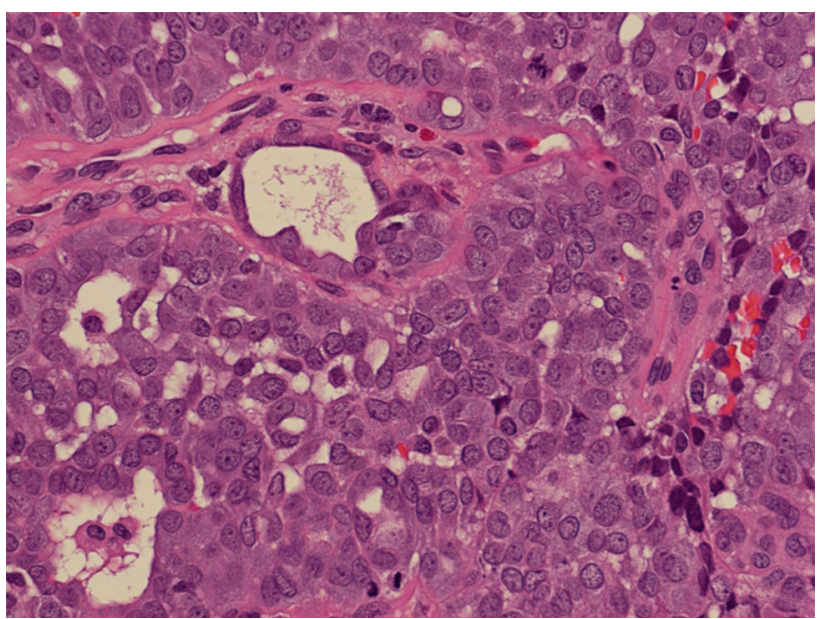

Fig. 6 High-grade nonintestinal-type adenocarcinoma of nasal cavity. This high-grade tumor is poorly differentiated and displays atypical mitotic figures. It has areas of glandular differentiation, but does not exhibit intestinal or salivary-type features. H-E stain $\times 400$

Low-grade nonintestinal-type adenocarcinomas are uncommon (13\% of sinonasal adenocarcinomas) and occur mostly in the ethmoid sinus, the nasal cavity, and the 
maxillary sinuses. The age range is wide with a mean of $37-53$ years. Synonyms in the literature include terminal tubulus adenocarcinoma [35], sinonasal tubulopapillary low-grade adenocarcinoma [36, 37], sinonasal low-grade adenocarcinoma [34], and sinonasal seromucinous adenocarcinoma [38]. These carcinomas have no known association with environmental carcinogens.

Histopathologically, low-grade nonintestinal-type carcinomas exhibit varied architectural forms with exophytic papillae and tubular or glandular patterns [36, 39, 40] (Fig. 7). Trabecular, cribriform, clear cell and mucinous patterns have also been reported. The papillae and glands are usually lined by a single layer of uniform columnar or cuboidal cells with only minor cytologic aberrations. They show a bland low-grade cytology with round, uniform nuclei and inconspicuous nucleoli (Fig. 8). Mitotic figures are very rare. In these bland tumors, complexity of the growth pattern and local invasive growth are findings supporting a diagnosis of malignancy. Immunohistochemically, they are constantly positive for CK7, but usually negative for CK20 and CDX-2. Some $20 \%$ of these tumors associate with sinonasal seromucinous hamartomas or respiratory epithelial adenomatoid hamartomas [39, 41, $42]$. Due to positivity for markers of seromucinous differentiation such as DOG1, SOX10, and S-100, a subset of these carcinomas was called sinonasal seromucinous adenocarcinomas [42].

Differential diagnosis of low-grade nonintestinal-type adenocarcinoma includes ITAC, acinic cell carcinoma, oncocytic Schneiderian papilloma and, rarely, metastatic papillary carcinoma of the thyroid. Differentiation of these low-grade carcinomas from ITAC is highly important in view of the distinct behaviors of the two neoplasms. The

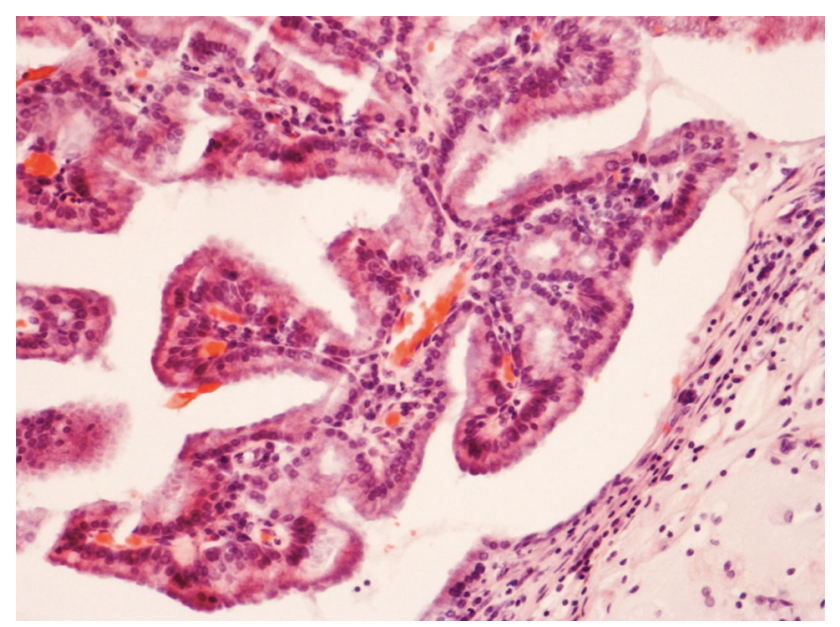

Fig. 7 Low-grade nonintestinal-type adenocarcinoma of nasal cavity. A complex papillary growth pattern with some glandular structures. A single layer of bland columnar cells line the papillae. Nuclear pleomorphism is minimal and no mitotic figures are seen $\times 400$

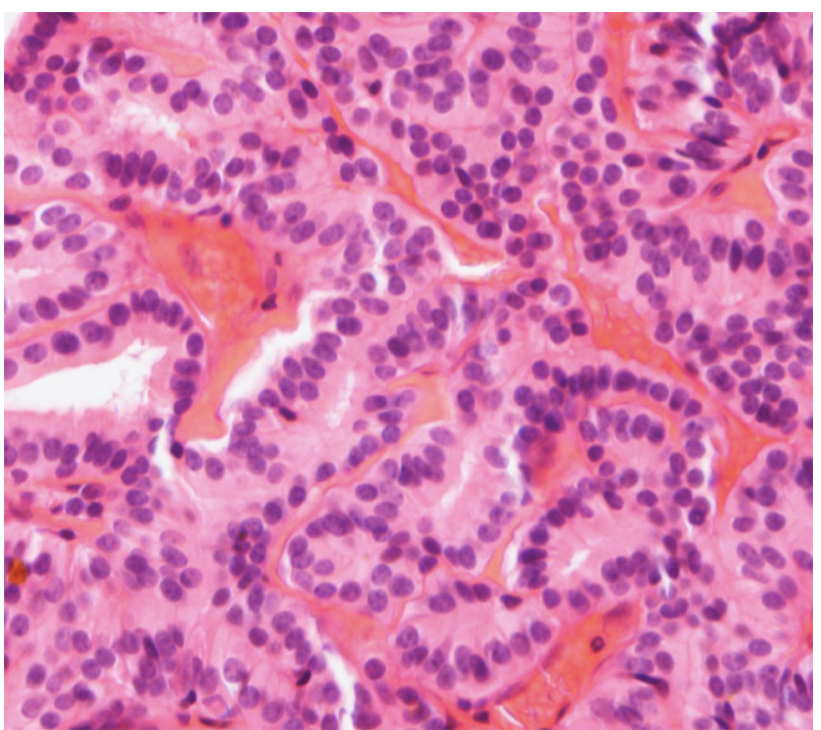

Fig. 8 Low-grade nonintestinal-type adenocarcinoma, tubulopapillary pattern. A papillary and tubular growth pattern with a single layer of cuboidal to columnar cells with round uniform nuclei, indistinct nucleoli and eosinophilic cytoplasm. H-E stain $\times 400$

defined growth patterns and high nuclear grade of ITAC usually allow for a clear-cut differential diagnosis. Immunohistochemically, low-grade nonintestinal-type adenocarcinomas remain negative for CK20, CDX-2 and MUC2. However, rare ITACs that resemble normal intestinal mucosa may present a source of confusion. Even such bland-looking ITACs are potentially high-grade malignancies. Oncocytic Schneiderian papillomas may be confused with low-grade nonintestinal-type adenocarcinomas although the epithelium of papillomas is multilayered and does not contain true glandular lumina [34]. Metastatic papillary carcinoma of the thyroid can be distinguished with stains for TTF-1 and thyroglobulin.

The treatment of low-grade nonintestinal-type adenocarcinoma is complete surgical removal, and radical procedures are seldom needed. Radiotherapy is optional. The disease is usually localized, but local recurrences are possible [34]. Metastasis is unusual, and death of disease is rare. The overall prognosis of the patients is favorable.

Open Access This article is distributed under the terms of the Creative Commons Attribution 4.0 International License (http://crea tivecommons.org/licenses/by/4.0/), which permits unrestricted use, distribution, and reproduction in any medium, provided you give appropriate credit to the original author(s) and the source, provide a link to the Creative Commons license, and indicate if changes were made.

\section{References}

1. Gnepp DR, Heffner DK. Mucosal origin of sinonasal tract adenomatous neoplasms. Mod Pathol. 1989;2:365-71. 
2. Eveson J. Salivary gland-type carcinomas. WHO histological classification of tumors of the nasal cavity and paranasal sinuses. In: Barnes L, Eveson JW, Reichardt P, Sidransky D, editors. Pathology \& genetics, head and neck tumors. Lyon: IARC Press; 2005. p. 24-5.

3. Batsakis JG, Rice DH, Solomon AR. The pathology of head and neck tumors: squamous and mucous-gland carcinomas of the nasal cavity, paranasal sinuses, and larynx. Part 6. Head Neck Surg. 1980;2:497-508.

4. Thompson LDR, Penner C, Ho NJ, Foss RD, Miettinen M, Wieneke JA, Moskaluk CA, Stelow EB. Sinonasal tract and nasopharyngeal adenoid cystic carcinoma: a clinicopathologic and immunophenotypic study of 86 cases. Head Neck Pathol. 2014;8:88-109.

5. Bishop JA, Ogawa T, Stelow EB, Moskaluk CA, Koch WM, Pai SI, Westra WH. Human papillomavirus-related carcinoma with adenoid cystic-like features. A peculiar variant of head and neck cancer restricted to the sinonasal tract. Am J Surg Pathol. 2013;37:836-44.

6. Wolfish EB, Nelson BL, Thompson LDR. Sinonasal tract mucoepidermoid carcinoma: a clinicopathologic and immunophenotypic study of 19 cases combined with a comprehensive review of the literature. Head Neck Pathol. 2012;6:191-207.

7. Storck K, Moh'd Hadi U, Simpson R, Ramer M, BrandweinGensler M. Sinonasal renal cell-like adenocarcinoma: a report on four patients. Head Neck Pathol. 2008;2:75-80.

8. Franchi A, Santucci M, Wenig BM. Adenocarcinoma. WHO histological classification of tumors of the nasal cavity and paranasal sinuses. In: Barnes L, Eveson JW, Reichardt P, Sidransky D, editors. Pathology \& genetics, head and neck tumors. Lyon: IARC Press; 2005. p. 20-1.

9. Barnes L. Intestinal-type adenocarcinoma of the nasal cavity and paranasal sinuses. Am J Surg Pathol. 1986;10:192-202.

10. Franquemont DW, Fechner RE, Mills SE. Histologic classification of sinonasal intestinal-type adenocarcinoma. Am J Surg Pathol. 1991;15:368-75.

11. Acheson ED, Hadfield EH, Macbeth RG. Carcinoma of the nasal cavity and accessory sinuses in woodworkers. Lancet. 1967;11:311-2.

12. Imbus HR, Dyson WL. A review of nasal cancer in furniture manufacturing and woodworking in North Carolina, the United States, and other countries. J Occup Med. 1987;29:734-40.

13. Ironside P, Matthews J. Adenocarcinoma of the nose and paranasal sinuses in woodworkers in the state of Victoria, Australia. Cancer. 1975;36:1115-21.

14. IARC monographs on the evaluation of carcinogenic risks to humans. Volume 62: wood dust and formaldehyde. Lyon: IARC; 1995.

15. Leclerc A, Luce D, Demers PA, et al. Sinonasal cancer and occupation. Results from the reanalysis of twelve case-control studies. Am J Ind Med. 1997;31:153-65.

16. Moran CA, Wenig BM, Mullick FG. Primary adenocarcinoma of the nasal cavity and paranasal sinuses. Ear Nose Throat J. 1995;70:821-8

17. IARC Monographs on the evaluation of carcinogenic risks to humans. Volume 25: wood, leather and some associated industries. Lyon: IARC;1981.

18. Franchi A, Miligi L, Palomba A, Giovannetti L, Santucci M. Sinonasal carcinomas: recent advances in molecular and phenotypic characterization and their clinical implications. Crit Rev Oncol/Hematol. 2011;79:265-77.

19. Kleinsasser O, Schroeder H-G. Adenocarcinoma of the inner nose after exposure to wood dust. Morphological findings and relationships between histopathology and clinical behavior in 79 cases. Arch Otolaryngol. 1988;245:1-15.
20. Mills SE, Fechner RE, Cantrell RW. Aggressive sinonasal lesion resembling normal intestinal mucosa. Am J Surg Pathol. 1982;6:803-9.

21. Kennedy MT, Jordan RC, Berean KW, et al. Expression pattern of CK7, CK20, CDX-2, and villin in intestinal-type sinonasal adenocarcinoma. J Clin Pathol. 2004;57:932-7.

22. Franchi A, Massi D, Palomba A, Biancalani M, Santucci M. CDX-2, cytokeratin 7 and cytokeratin 20 immunohistochemical expression in the differential diagnosis of primary adenocarcinomas of the sinonasal tract. Virchows Arch. 2004;445:63-7.

23. Cathro HP, Mills SE. Immunophenotypic differences between intestinal-type and low-grade papillary sinonasal adenocarcinomas. An immunohistochemical study of 22 cases utilizing CDX2 and MUC2. Am J Surg Pathol. 2004;28:1026-32.

24. Franchi A, Fondi C, Pagleriani M, Pepi M, Gallo O, Santucci M. Epidermal growth factor receptor expression and gene copy number in sinonasal intestinal type adenocarcinoma. Oral Oncol. 2009;45:835-8.

25. Lopez F, Inclan CG, Pérez-Escuredo J, Marcos CA, Scola B, Suarez C, Llorente JL, Hermsen MA. KRAS and BRAF mutations in sinonasal cancer. Oral Oncol. 2012;48:692-7.

26. Projetti F, Durand K, Chaunavel A, Léobon S, Lacorre S, Caire F, Bessède JP, Moreau JJ, Coulibaly B, Labrousse F. Epidermal growth factor receptor expression and KRAS and BRAF mutations: study of 39 sinonasal intestinal-type adenocarcinomas. Hum Pathol. 2013;44:2116-25.

27. Franchi A, Innocenti DRD, Palomba A, Miligi L, Paiar F, Franzese C, Santucci M. Low prevalence of K-RAS, EGF-R and BRAF mutations in sinonasal adenocarcinomas. Implications for anti-EGFR treatments. Pathol Oncol Res. 2014;20:571-9.

28. Perez-Ordonez B, Huynh NN, Berean KW, Jordan RCK. Expression of mismatch repair proteins, $\beta$ catenin, and $\mathrm{E}$ cadherin in intestinal-type sinonasal adenocarcinoma. J Clin Pathol. 2004;57:1080-3.

29. Projetti F, Mesturoux L, Coulibaly B, Durand K, Chaunavel A, Léobon S, Gadeaud E, Caire F, Bessède JP, Labrousse F. Study of MET protein levels and MET gene copy number in 72 sinonasal intestinal-type adenocarcinomas. Head Neck. 2014;37:1563-8.

30. Rodrigo JP, Garcia-Pedrero JM, Llorente JL, Fresno MF, Allonca E, Suarez C, Hermsen M. Down-regulation of annexin A1 and A2 protein expression in intestinal-type sinonasal adenocarcinomas. Hum Pathol. 2011;42:88-94.

31. Holmila R, Bornholdt J, Heikkilä P, Suitiala T, Févotte J, Cyr D, Hansen J, Snellman SM, Dictor M, Steinicke T, Schlunssen V, Schneider T, Pukka E, Savolainen K, Wolff H, Wallin H, Luce D, Husgafvel-Pursiainen K. Mutations in TP53 tumor suppressor gene in wood dust-related sinonasal cancer. Int $\mathrm{J}$ Cancer. 2010;127:578-88.

32. Tilson MP, Gallia GL, Bishop JA. Among sinonasal tumors, CDX-2 immunoexpression is not restricted to intestinal-type adenocarcinomas. Head Neck Pathol. 2014;8:59-65.

33. Stelow EB, Jo VY, Mills SE, Carlson DL. A histologic and immunohistochemical study describing the diversity of tumors classified as sinonasal high-grade nonintestinal adenocarcinomas. Am J Surg Pathol. 2011;35:971-80.

34. Heffner DK, Hyams VJ, Hauck KW, et al. Low-grade adenocarcinoma of the nasal cavity and paranasal sinuses. Cancer. 1982;50:312-22.

35. Kleinsasser $\mathrm{O}$. Terminal tubulus adenocarcinoma of the nasal seromucous glands. A specific entity. Arch Otorhinolaryngol. 1985;241:1-15.

36. Skalova A, Cardesa A, Leivo I, Pfaltz M, Ryska A, Simpson R, et al. Sinonasal tubulopapillary low-grade adenocarcinoma. Histopathological, immunohistochemical and ultrastructural features of poorly recognized entity. Virchows Arch. 2003;443:152-8. 
37. Leivo I. Update on sinonasal adenocarcinoma: classification and advances in immunophenotype and molecular genetic make-up. Head Neck Pathol. 2007;1:38-43.

38. Neto AG, Pineda-Daboin K, Luna MA. Sinonasal tract seromucous adenocarcinomas: a report of 12 cases. Ann Diagn Pathol. 2003;7:154-9.

39. Jo VY, Mills SE, Cathro HP, Carlson DL, Stelow EB. Low-grade sinonasal adenocarcinomas. The association with and distinction from respiratory epithelial adenomatoid hamartomas and other glandular lesions. Am J Surg Pathol. 2009;33:401-8.

40. Weinreb I. Low-grade glandular lesions of the sinonasal tract: a focused review. Head Neck Pathol. 2010;4:77-83.
41. Weinreb I, Gnepp DR, Laver NM, Hoschar AP, Hunt JL, Seethala RR, Barnes EL, Chetty R, Perez-Ordonez B. Seromucinous hamartomas: a clinicopathological study of a sinonasal glandular lesion lacking myoepithelial cells. Histopathology. 2009;54: 205-13.

42. Purgina B, Bastaki JM, Duvvuri U, Seethala RR. A subset of sinonasal non-intestinal type adenocarcinomas are truly seromucinous adenocarcinomas: a morphologic and immunophenotypic assessment and description of a novel pitfall. Head Neck Pathol. 2015;9:436-46. 